\title{
A NEW METHOD TO CALCULATE ALLOMETRIC LENGTH-MASS RELATIONSHIPS OF DINOSAURS
}

\author{
Author(s) :FRANK SEEBACHER
}

Source: Journal of Vertebrate Paleontology, 21(1):51-60. 2001.

Published By: The Society of Vertebrate Paleontology

DOI: http://dx.doi.org/10.1671/0272-4634(2001)021[0051:ANMTCA]2.0.CO;2

URL: http://www.bioone.org/doi/full/10.1671/0272-4634\%282001\%29021\%5B0051\%3AANMTCA

$\% 5 \mathrm{D} 2.0 . \mathrm{CO} \% 3 \mathrm{~B} 2$

BioOne (www.bioone.org) is a nonprofit, online aggregation of core research in the biological, ecological, and environmental sciences. BioOne provides a sustainable online platform for over 170 journals and books published by nonprofit societies, associations, museums, institutions, and presses.

Your use of this PDF, the BioOne Web site, and all posted and associated content indicates your acceptance of BioOne's Terms of Use, available at www.bioone.org/page/terms_of_use.

Usage of BioOne content is strictly limited to personal, educational, and non-commercial use. Commercial inquiries or rights and permissions requests should be directed to the individual publisher as copyright holder. 


\title{
A NEW METHOD TO CALCULATE ALLOMETRIC LENGTH-MASS RELATIONSHIPS OF DINOSAURS
}

\author{
FRANK SEEBACHER \\ School of Biological Sciences A08, University of Sydney, New South Wales 2006, Australia
}

\begin{abstract}
Body mass is an important determinant of most biological functions, and knowing the mass of extinct animals is essential in order to learn about their biology. It was the aim of this paper to develop a method of mass estimation which would make it possible to determine allometric length-mass relationships for the different groups of dinosaurs. Mass is calculated from graphical reconstructions of fossils, or from photos of skeletal mounts or live animals. Body shape of animals is described by high order polynomial equations. Integration of the polynomial gives body mass of a 'round' animal, which is then corrected for animal width by intersection with a second equation $(\mathrm{Y}=$ $1-\mathrm{ax}^{2}$ ). The method was validated by predicting body mass of extant animals of known mass and with complex body shapes (kangaroos, emu, elephant, giraffe, rhinoceros). Body mass increased allometrically with total length in all groups of dinosaurs (Ankylosauria, Ceratopsia, Ornithopoda, Prosauropoda, Sauropoda, Stegosauria and Theropoda), but $95 \%$ confidence intervals were very large for Ankylosauria and Stegosauria so that, for those groups, the resulting regression equations have little predicting power. Scaling exponents were least for the Sauropoda which may have grown less massive to function at their great body size. Scaling exponents were greatest for the Theropoda, but it was speculated that small coelurosaurs, as the precursors of birds, may have grown less massive compared to other theropods. Mass estimated by the 'polynomial' method presented here did not differ significantly from mass estimates in the literature where these were available.
\end{abstract}

\section{INTRODUCTION}

The dinosauria underwent an extraordinary radiation over more than 150 million years, and one of the most striking features about dinosaurs is the great range of sizes they achieved which is unparalleled among terrestrial animals. This great diversity raises many biological questions about their physiology (Spotila et al., 1991; Reid, 1997), morphology (Alexander, 1985; Christiansen, 1997) and ecology (Dunham et al., 1989; Farlow, 1993). In order to answer most of these questions, however, it is necessary to estimate body mass. The rate of most biological processes, for example metabolic rate (Coulson and Hernandez, 1983), thermal physiology (Seebacher et al., 1999), and digestion (Schmidt-Nielsen, 1984), change with body mass according to well known but complex scaling laws (SchmidtNielsen, 1984; West et al., 1997).

A number of different techniques, such as measuring the volume of scale models (Colbert, 1962; Alexander, 1985; Farlow et al., 1995; Paul, 1988), relating bone circumference to body mass (Anderson et al., 1985), and using the mathematical method of 3-D slicing (Henderson, 1999), have been applied already to estimate dinosaur body mass. Similar techniques have also been used to estimate mass of other extinct animals, notably that of extinct mammals whose mass was estimated from osteological measurements of a large number of modern species within that group (Christiansen, 1999a). Also, the mass of the pelycosaur Edaphosaurus has been estimated by graphic double integration, whereby the sum of the volumes of numerous cylinders into which the body is divided gives an estimate of total mass, as well as by extrapolations from osteological measurements and length-mass relationships of extant mammals and alligators (Hurlburt, 1999).

The aims of this study were to develop a computationally simple method to estimate mass of dinosaurs from reconstructions published in the literature. The value of such a method would lie in the fact that, because graphical reconstructions are easily accessible, it would be possible to estimate body mass of a comparatively large number of species so that allometric relationships of dinosaurs could be determined. Hence, it was the second aim of this study to find power equations relating body mass to body length of the major taxonomic groups of dinosaurs. Such allometric equations would be very useful for future studies and they would make it possible, for example, to determine body mass of newly discovered dinosaurs, because body length can be derived from (relatively complete) fossils.

The method I developed to estimate body mass of living and extinct animals relies on describing the two-dimensional outline of animals mathematically, and then integrating to estimate the volume and, hence, mass, after correcting for body width. The validity of the technique was tested by estimating the mass of extant animals for which independent mass measurements are available, and which represent a great diversity of body shapes.

\section{MATERIALS AND METHODS}

The technique presented is an extension of methods used to calculate the mass of crocodiles over a great size range (2.6$1,010 \mathrm{~kg}$ ), where it worked very well when validated against empirical data (Seebacher et al., 1999). However, crocodiles are of relatively simple body shape, and the technique was further developed here to include more complex body shapes. Hence, the validity of predictions was tested by estimating the mass of animals with complex and varied body shape. Photographs of museum specimens (Zoology Museum, University of Queensland, Brisbane, Australia) were taken to estimated the mass of taxidermic mounts of Red Kangaroos (Macropus rufus) and a Red-necked Wallaby (Macropus rufogriseus), as well as of skeletal mounts of M. rufogriseus (Fig. 1) and an emu, Dromaius novaehollandiae. In addition, I determined the mass of an elephant (Elphas maximus), a giraffe (Giraffa camelopardalis), and a rhinoceros (Diceros bicornis) from photographs published in Walker et al. (1964). Photographs of museum specimens were used rather than measurements of the specimens themselves in order to emulate the two dimensional character of dinosaur reconstructions in the literature. Body mass for $\mathrm{Ma}$ cropus was also determined independently from allometric field data relating hind foot length to body mass (Tony Pople, unpubl. data), and ranges of body mass for the emu, giraffe, elephant and rhinoceros were taken from the literature (Table 1).

Dinosaur body dimensions, from which mass estimates were 


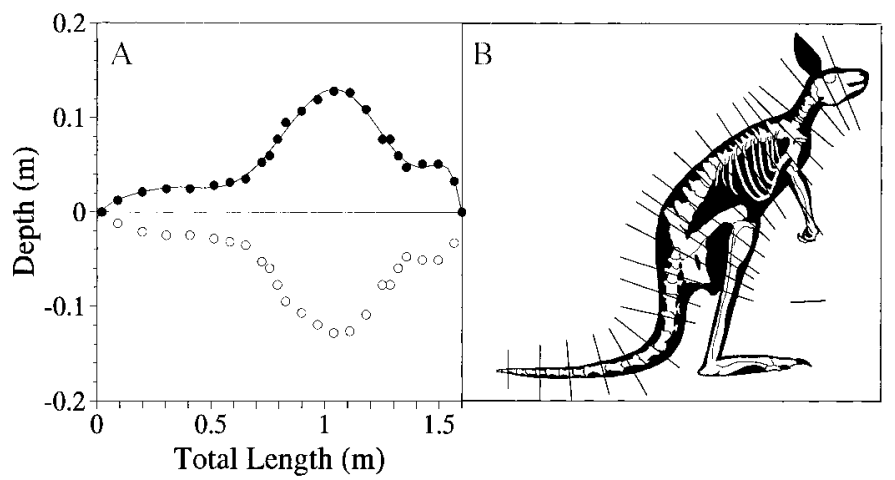

FIGURE 1. Macropus rufogriseus as an example to demonstrate the method used to calculate dinosaur body mass. The depth of the animal was measured at regular intervals from a skeletal reconstruction (right panel). The measured depth was then plotted in a cartesian coordinate system with $\mathrm{y}=0$ as the body midline. A polynomial (solid line) was fitted to the depth measurements (solid circles) at the dorsal surface (=half total depth). The volume of revolution of the polynomial was determined by integration over the total length.

made, were determined from published reconstructions separately for ankylosauria, marginocephalia, ornithopoda, prosauropoda, sauropoda, stegosauria, and theropoda (see Table 2 for references). An effort was made to use reconstructions based on particular museum specimens. However, these were not always available, and some reconstructions were used which identified specimens by genus only and which made no reference to particular fossil specimens (Table 2).

The two-dimensional outline of animals was described by polynomial equations which were fitted to measurements taken from photographs or drawings (see below). Polynomials were fitted to the measured values by the Marquardt-Levenberg method in CurveExpert 1.2 software. Note that polynomials are a mathematical series of the form

$$
\mathrm{Y}=\mathrm{a}_{0} \mathrm{x}^{0}+\mathrm{a}_{1} \mathrm{X}^{1}+\mathrm{a}_{2} \mathrm{X}^{2} \ldots \mathrm{a}_{\mathrm{n}} \mathrm{x}^{\mathrm{n}}
$$

where in the present case $\mathrm{x}=$ total length $(\mathrm{m})$ and $\mathrm{Y}=$ mass $(\mathrm{kg})$. As with most mathematical series, the precision of the solution will increase the more terms are added to the series. In practical terms, this means that very simple animal shapes, such as the outline of a crocodile, can be described adequately by a second order polynomial (Seebacher et al., 1999), but the mathematical description of more complex shapes, such as those of dinosaurs or kangaroos, require higher order polynomials. Hence, in all mass estimates reported below, eighth order polynomials were used to describe body outlines.
The depth of the body was defined and measured as the linear distance between the ventral and dorsal surfaces perpendicular to the vertebral column. Measurements were taken at regular intervals of no more than $10 \%$ of total length for 'regular' sections of the body, such as long tails, but at intervals of less than 5\% for more 'irregular' sections, such as the pectoral and pelvic girdles (Fig. 1B). The measured depth was then plotted in a cartesian coordinate system with $\mathrm{y}=0$ as the centreline of the body, and the polynomial was fitted to the positive $y-$ values $(0.5$ total depth $=$ dorsal surface; Fig. $1 \mathrm{~A})$.

Integration of the polynomial [ $\mathrm{f}(\mathrm{x})$ ] over the total length of the animal gives the volume of the round animal; the volume of revolution of any equation is calculated as $\mathrm{V}=\pi \int \mathrm{f}(\mathrm{x})^{2} \mathrm{dx}$ (Stewart, 1991). The volume was multiplied by the density to give an estimate of mass. Density was assumed to be $1,000 \mathrm{~kg}$ $\mathrm{m}^{3}$ for all animals (Alexander, 1989; Hurlburt, 1999) except for the emu where it was assumed to be $850 \mathrm{~kg} \mathrm{~m}^{3}$ to account for airsacks. It is likely that some theropoda possessed airsacks, but the extent of their occurrence is not known (Ruben et al., 1997). Hence, to avoid unnecessary speculation, I followed Alexander (1989) and Hurlburt (1999), except for the emu which undoubtably have airsacks.

Few animals are round, however, so that mass estimates of 'round' animals described above have to be corrected for width. Again, the width of dinosaurs was estimated from skeletal reconstructions. However, relatively few published reconstructions represent cross-sections or 'top-down' views of dinosaurs, so that available width measurements were applied also to other species within the same taxonomic group for which there were no width estimate available. For example, ratios of depth: width (see below) which were based on measurements of Sauropelta (Carpenter, 1984) were assumed to be applicable also to Nodosaurus. Cross-sectional or top-down views were available for some species of each taxonomic group (Borsuk-Bialynicka, 1977; Carpenter, 1981, 1984; Lucas, 1994; McIntosh, 1997; Paul, 1988, 1990; Sereno, 1990) except for prosauropods which were assumed to be of similar shape as sauropods. In addition, width was also determined from skeletal reconstructions of Muttaburrasaurus (QM F6140) and Probactrosaurus (a cast of MHP 2231/1) kept at the Queensland Museum, Brisbane, Australia. Again, two-dimensional photographs of the specimens of Muttaburrasaurus and Probactrosaurus were used rather than taking measurements on the three dimensional reconstructions.

Width and depth were measured at the same point of the body, which gives a ratio of the linear measurements of width: depth. However, because the lateral surfaces of animals do not follow straight lines, the linear width: depth ratio has to be translated to a more curvaceous shape. Hence, the actual shape of animals was represented by a curve with the equation

TABLE 1. Total length $(\mathrm{m})$ and body mass $(\mathrm{kg})$ of extant animals of various body shapes estimated by the 'polynomial' method. Independent mass estimates are also given, and these are based on allometric field data for Macropus or on values in the literature. Sources for the specimens or photos used to estimate mass by the polynomial method, and sources for independent mass estimates are given.

\begin{tabular}{|c|c|c|c|c|c|}
\hline \multirow[b]{2}{*}{ Species } & \multirow[b]{2}{*}{ TL } & \multicolumn{2}{|c|}{ Estimated } & \multicolumn{2}{|c|}{ Independent } \\
\hline & & Mass & Source & Mass & Source \\
\hline Macropus rufus (male) ${ }^{1}$ & 2.07 & 63.4 & UQZM & 62.9 & Field Data \\
\hline Macropus rufus (female) ${ }^{1}$ & 1.51 & 21.3 & UQZM & 24.4 & Field Data \\
\hline Macropus rufogriseus ${ }^{2}$ & 1.50 & 20.8 & UQZM & 21.5 & Field Data \\
\hline Dromaius novahollandiae $^{3}$ & 1.52 & 18.4 & UQZM & $30-55$ & del Hoyo et al. (1992) \\
\hline Elphas maximus & 5.53 & $4,855.7$ & Walker (1964) & 5,000 & Walker (1964) \\
\hline Giraffa camelopardalis & 3.74 & 899.7 & Walker (1964) & $550-1,800$ & Walker (1964) \\
\hline
\end{tabular}

${ }^{1}$ Taxidermic mount.

${ }^{2}$ Skeletal reconstruction.

${ }^{3}$ Skeletal reconstruction of juvenile or small adult. 
TABLE 2. Mass estimates ( $\mathrm{kg}$ ) of dinosaurs determined by the 'polynomial' technique. The total length (TL, m) as well as the reference in which reconstructions were published are given. Species names and museum numbers of specimens on which reconstructions were based are given where available.

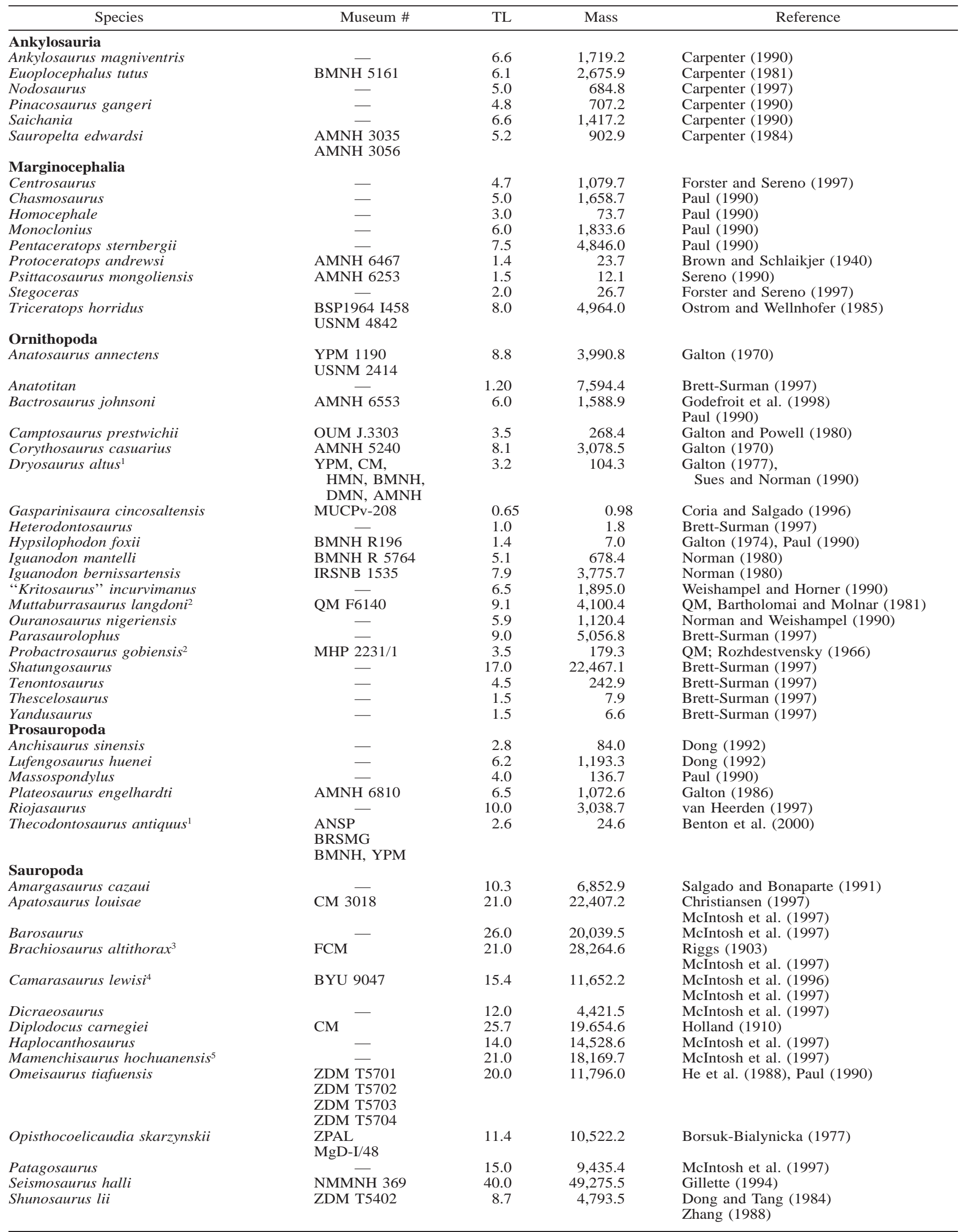


TABLE 2. (Continued)

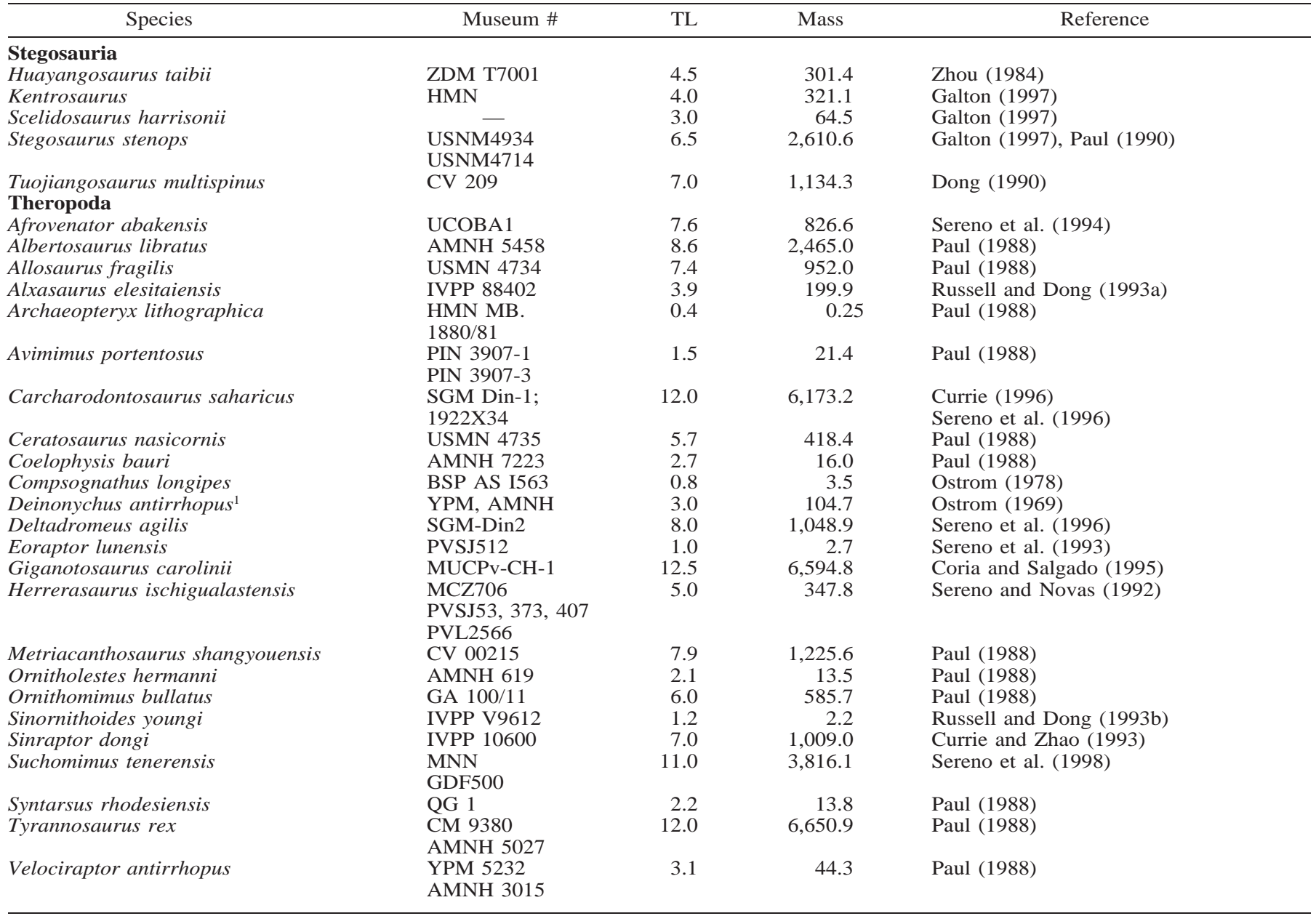

${ }^{1}$ Numerous fragments kept at the museums listed.

${ }^{2}$ Mass estimates were based on photos, taken by the author, of skeletal reconstructions at the Queensland Museum, Brisbane, Australia. The original fossil descriptions are given in the references.

${ }^{3}$ The reconstruction of Brachiosaurus in McIntosh et al. (1997) does not give species name or museum locality. The length of the femur and humerus are consistent, however, with the description of $B$. altithorax given in Riggs (1903) who comments on the great length of the femur in this species.

${ }^{4}$ As for Brachiosaurus, species name and museum catalog numbers are not given for the graphical reconstruction of Camarasaurus in McIntosh et al. (1997). The length of the femur given by McIntosh et al. (1997) seems to indicate, however, that the reconstruction is of C. lewisi, based on comparative data given in McIntosh et al. (1996).

${ }^{5}$ The reconstruction of Mamenchisaurus in McIntosh et al. (1997) fits the description of M. hochuanensis given in Dong (1992), and for which a complete specimen exists. The other species, M. constructus, is known from an incomplete specimen only.

$$
\mathrm{y}=1-\mathrm{ax}^{2}
$$

where $\mathrm{y}=$ depth, $\mathrm{x}=$ width, and the linear width: depth ratio $=(1 / \mathrm{a})^{0.5}$ (Fig. 2). In Fig. 2, the cross-sections of a 'round' body shape and that of a realistically shaped hypothetical animal are shown, and the ratio between the areas under the curves $\left(1-\mathrm{ax}^{2}\right.$ :round $)$ in, for example, the positive quadrant is the same as the ratio between the volumes of the 'round' animal and an animal with realistic $\left(1-\mathrm{ax}^{2}\right)$ body shape. Hence, the areas under the two curves were determined by integrating in the positive quadrant of the coordinate system, and the final body volume, and mass, were calculated by multiplying the mass estimate of the round animal shape by the ratio of the areas under these curves.

For example, squaring and integrating the polynomial fitted to the data from the wallaby (Fig. 1B) and multiplying by density gives a body mass of $28.1 \mathrm{~kg}$ for the round shape. The linear ratio between width and depth was only 0.87 , however, so that using the volume of a round animal would lead to an overestimate of body mass. The area under the curve of $y=1$ $-\mathrm{ax}^{2}$ was calculated from the measured width: depth ratio, to give the ratio of the integrals of $1-\mathrm{ax}^{2}$ : circle which was 0.74 , so that the final body mass was $28.1 * 0.74=20.8 \mathrm{~kg}$.

Leg mass was calculated separately, and legs were assumed to be cylinders. Length and width of the legs was determined from reconstructions, and leg width was measured at intervals of at least $10 \%$ total leg length. The width was then averaged for the whole length to give the diameter of the cylinder.

Non-linear regression equations were fitted to calculated mass (y) and total length (x) data using least-squares regression procedures in Systat 8.0 (SPSS Inc.) software. Model I regression was chosen, because total length was assumed to be fixed in the analysis, and the high coefficients of determination (Table 3 ) indicate that the regression model was appropriate and that it explained most of the variation in the data (Sokal and Rohlf, 1981). All regressions are presented as allometric power equations, i.e., Mass $=$ aTotal Length $^{\mathrm{b}}$, and $95 \%$ confidence intervals were calculated for the exponent. 


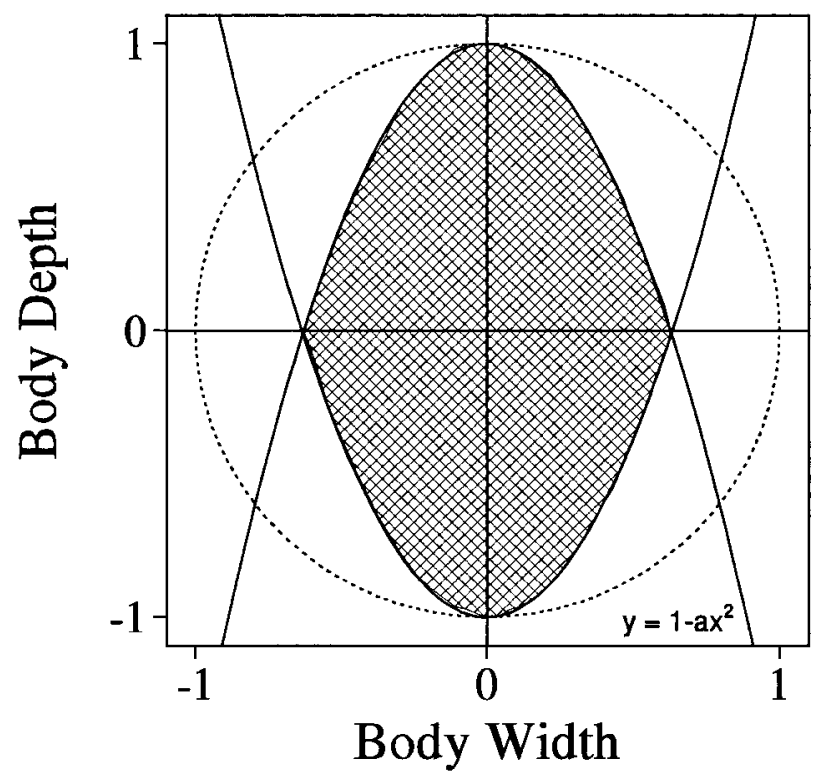

FIGURE 2. Body mass of the round animal is corrected for real animal width by superimposing the curve $\mathrm{Y}=1-\mathrm{ax}^{2}$ (solid line) onto a cross section of the round body shape (dotted line). Note that in order to show the resulting animal shape (hatched area) $\mathrm{Y}=1-\mathrm{ax}^{2}$ as well as $\mathrm{Y}=-\left(1-\mathrm{ax}^{2}\right)$ were plotted. The ratio of areas under the curves of the circle and $Y=1-a x^{2}$ in the positive quadrant, for example, is the same as the ratio of their respective volumes. Hence, by integrating the two curves in the positive quadrant, and multiplying the volume of the round animal by the ratio of the integrals, the mass of the realistically shaped animals could be determined.

Museum Abbreviations: AMNH, American Museum of Natural History, New York, USA; ANSP, Academy of Natural Sciences, Philadelphia, USA; BMNH, British Museum (Natural History), London, UK; BRSMG, Bristol City Museum and Art Gallery, Bristol, UK; BSP, Bayrische Staatssammlungen für Paläontologie, Munich, Germany; BYU, Brigham Young University, Provo, USA; CM, Carnegie Museum, Pittsburgh, USA; CV, Municipal Museum of Chungking, China; DNM, Dinosaur National Monument, Utah, USA; FCM, Field Columbian Museum, Columbia, USA; GI, Geological Institute, Ulan Bator, Mongolia; HMN, Humboldt Museum für Naturkunde, Berlin, Germany; IRSNB, Institut Royal des Sciences Naturelles de Belgique, Brussels, Belgium; IVPP, Institut of Vertebrate Paleontology and Paleoanthropology, Beijing, China; $\mathbf{M C Z}, \mathbf{M u}-$ seum of Comparative Zoology, Cambridge, UK; MNN, Musée National du Niger, Niger; NMMNH, New Mexico Museum of Natural History, Albuquerque, USA; OUM, Oxford University Museum, Oxford, UK; PIN, Palaeontological Institute, Moscow, Russia; PVSJ, Museo de Ciencias Naturales, Universitdad Nacional de San Juan, San Juan, Argentinia; QG, Queen Victoria Museum, Salisbury, UK; QM, Queensland Museum, Brisbane, Australia; SGM, Ministère de l'Energie et des Mines, Rabat, Morocco; UCOBA, University of Chicago, Chicago, USA; UQZM, University of Queensland Zoology Museum, Brisbane, Australia; USNM, United States National Museum, Washington DC, USA; YPM, Peabody Museum Yale University, New Haven, USA; ZDM, Zigong Dinosaur Museum, Sichuan, China; ZPAL, Institut of Paleobiology, Polish Academy of Sciences, Warsaw, Poland.

\section{RESULTS AND DISCUSSION}

The 'polynomial' method reliably predicted body mass of extant animals (Table 1). For the four specimens of Macropus,
TABLE 3. Regression equations relating body mass (kg) to total length (m) for each taxonomic group of dinosaur. Regression equations are in the form $\mathrm{Y}=\mathrm{aX}$, and $95 \%$ confidence intervals for the exponent as well as coefficients of determination $\left(R^{2}\right)$ are given.

\begin{tabular}{lcccc}
\hline $\begin{array}{l}\text { Taxonomic } \\
\text { group }\end{array}$ & $\mathrm{a}$ & $\mathrm{b}$ & $\pm 95 \% \mathrm{CI}$ & $R^{2}$ \\
\hline Ankylosauria & 16.54 & 2.51 & 4.60 & 0.54 \\
Ceratopsia & 12.58 & 2.90 & 0.94 & 0.98 \\
Ornithopoda & 11.81 & 2.66 & 0.14 & 0.99 \\
Prosauropoda & 12.32 & 2.40 & 0.64 & 0.99 \\
Sauropoda & 214.44 & 1.46 & 0.36 & 0.86 \\
Stegosauria & 10.95 & 2.64 & 6.76 & 0.59 \\
Theropoda & 0.73 & 3.63 & 0.38 & 0.98 \\
\hline
\end{tabular}

the predicted 'polynomial' mass was within $6.1 \%$ (range $0.76-$ $14.6 \%$ ) of the independently determined mass which would be well within the naturally occurring variations between animals of the same body length. The specimen of Dromaius used is that of a juvenile or small adult. An adult emu stands 1.5-1.9 $m$ tall (del Hoyo et al., 1992) while the emu skeleton at the UQZM is $1.15 \mathrm{~m}$ tall, so that the lower mass estimate is reasonable.

The linear dimensions of Giraffa, Elphas, and Diceros were taken to lie in the middle of the range given by Walker et al. (1964), so that the mass estimates, which also lie in the middle of the range given (except for Elphas for which the mass was given as "about" $5,000 \mathrm{~kg}$ ), appear to be accurate and confirm the validity of the technique (Table 1 ).

Calculated mass of dinosaurs increased allometrically with body length (Table 2, Fig. 3). The high coefficients of determination $\left(R^{2}\right)$ associated with the curves fitted to the data (Table 3 ) indicate that the regression equations explain most of the variation in the data, except for Ankylosauria and Stegosauria where $R^{2}$ values were considerably less than for the other groups of dinosaurs. Similarly, small sample sizes and considerable variation between species resulted in very large $95 \%$ confidence intervals in the latter two groups so that the regression equations have very little predictive power. However, confidence intervals for the other groups of dinosaurs were relatively narrow given the statistically small sample sizes, and their magnitude is comparable to values reported for allometric equations relating body mass to osteological measurements in mammals (Christiansen, 1999b).

It is interesting to note that the slope (upper 95\% CI) for sauropods is less than that for the other groups. This means that sauropods grew less massive with increasing body length compared to other dinosaurs (excluding ankylosaurs and stegosaurs given their extremely wide confidence intervals). A similar relationships exists for the scaling of long bones in mammals where the regression slopes of small mammals are consistently steeper than for large mammals (Christiansen, 1999a). These patterns indicate that there may be special morphological adaptations to cope with great body mass in the larger taxa (Christiansen 1999a) which may be at least partly dictated by the need to maintain locomotory potential (Christiansen, 1997).

Body mass increase with body length was steepest in theropods, but allometric differences between theropoda, which were wholly bipedal, and other dinosaur groups, which were at least partly quadrupedal, may be explained by differences in their general body morphology. There may be reason to speculate, however, that small coelurosaurian theropods may have grown less massive than other theropods, because they may have shared mass-reducing morphological features with modern Aves which are believed to have evolved from small coelurosaurs (Padian et al., 1999; Sereno, 1999). Large coelurosaurs such as Tyrannosaurus, on the other hand, are likely to resemble other large (non-coelurosaurian) theropods as a result of size 

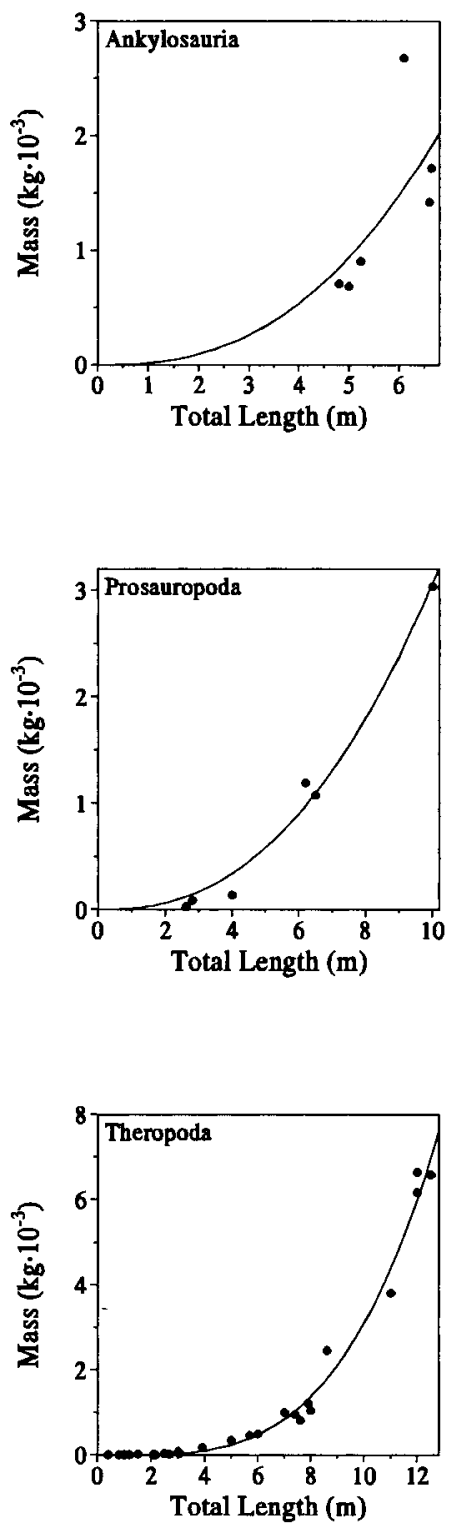
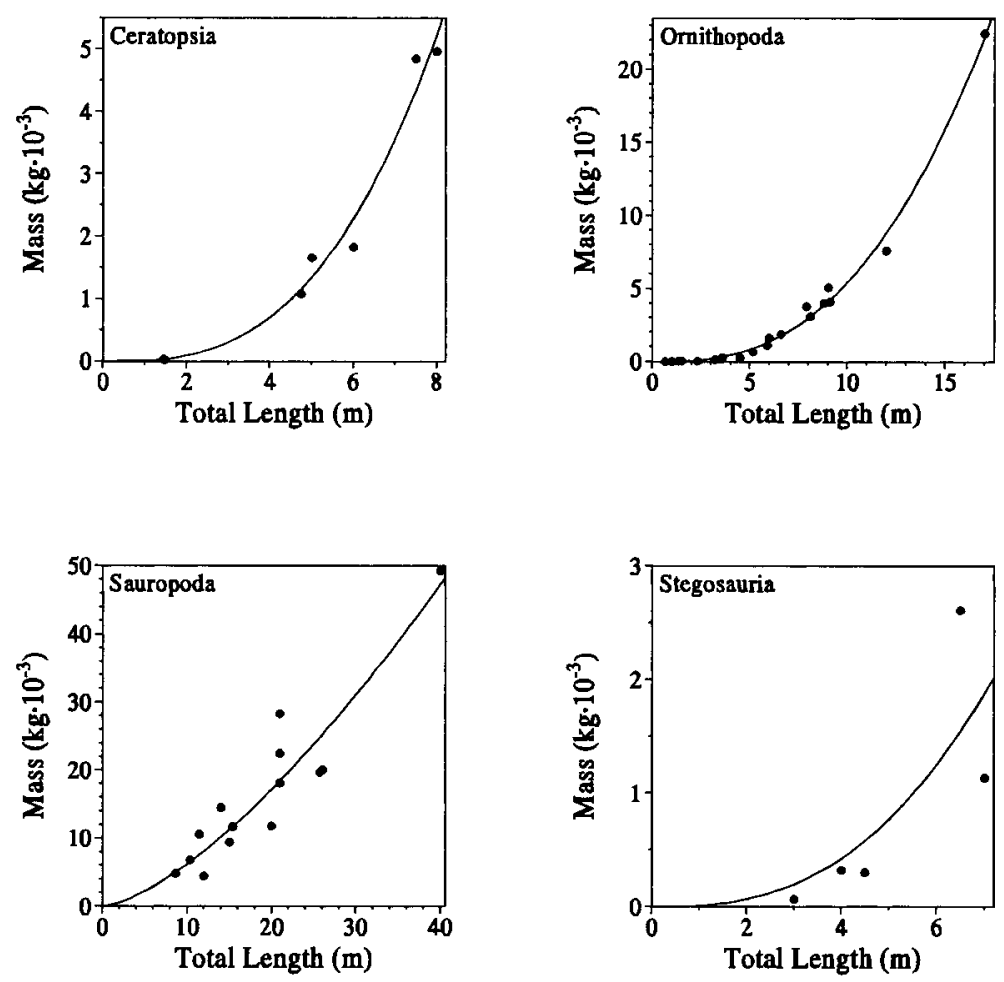

FIGURE 3. Calculated body mass of dinosaurs plotted against total length for each of the dinosaur groups. Details of the allometric equations (solid lines) fitted to the data are given in Table 3.

related convergence (Holtz, 1994). Note, however, that it is not known to what extent even small coelurosaurian theropod dinosaurs displayed anatomical features, such as airsacks, seen in modern birds (Ruben et al., 1997). The only evidence for the existence of airsacks comes from soft-tissue preservation in fossils of two small coelurosaurs (Dal Sasso and Signore, 1998; Martill et al., 2000), so that my argument here must be treated as speculative with respect to airsacks, although theropods undoubtably share numerous characteristics with Aves (Feduccia, 1999). Nonetheless, in order to explore a possible differences in scaling exponents between different groups of theropods, I repeated the regression analysis for theropods after dividing the data into "small coelurosaurs" (Alxasaurus, Archaeopteryx, Avimimus, Compsognathus, Deinonychus, Ornitholestes, Sinornithoides and Velociraptor) and "other" theropods. The regression slope for "small" coelurosaurs is indeed less (a = $\left.3.19, \mathrm{~b}=2.82 \pm 0.4095 \% \mathrm{CI}, R^{2}=0.99\right)$ than that for "other" theropods $(\mathrm{a}=0.69, \mathrm{~b}=3.65 \pm 0.5595 \% \mathrm{CI})$.

Most techniques which have been employed to estimate the mass of dinosaurs and other extinct animals are similar in that they are based on models or reconstructions from fossils (Colbert, 1962; Alexander, 1985; Paul, 1988; Farlow et al., 1995; Christiansen, 1997; Henderson, 1999; Hurlburt, 1999), except for mass estimates based on bone circumferences (Anderson et al., 1985). Hurlburt (1999) also presents methods which predict body mass of a pelycosaur from regression equations relating mass to either total length, or long bone dimensions of alligators and mammals. These methods would be inappropriate for dinosaurs, because dinosaur body shape is too complex and varied to make crocodilians an appropriate model organism. Moreover, long bones in mammals do not follow a uniform scaling relationship, but subgroups within the Mammalia scale differently (Christiansen, 1999a), so that assuming 'mammals' to be representative of 'dinosaurs' would be inappropriate.

Overall, my mass estimates do not differ significantly from estimates in the literature for the same species where these are available (two sample $t$-test: $t=-1.49$, df $=59, P=0.14$; Table 4), and there are no systematic differences between my 


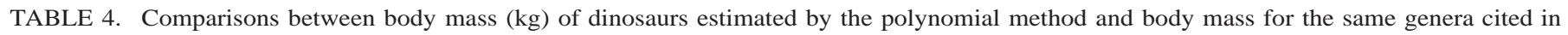
the literature.

\begin{tabular}{|c|c|c|c|}
\hline Genus & Polynomial mass & Literature mass & Reference \\
\hline \multicolumn{4}{|l|}{ Ceratopsia } \\
\hline Protoceratops & 23.7 & 177 & Colbert (1962) \\
\hline \multirow[t]{3}{*}{ Triceratops } & $4,963.6$ & 8,480 & Colbert (1962) \\
\hline & & 6,000 & Alexander (1989) \\
\hline & & 3,938 & Henderson (1999) \\
\hline \multicolumn{4}{|l|}{ Ornithopoda } \\
\hline Anatosaurus & $3,990.8$ & 3,070 & Colbert (1962) \\
\hline Camptosaurus & 268.4 & 383 & Colbert (1962) \\
\hline Corythosaurus & $3,078.5$ & 3,820 & Colbert (1962) \\
\hline Dryosaurus & 104.3 & 70 & Heinrich et al. (1993) \\
\hline \multirow{3}{*}{ Iguanodon } & $3,775.7$ & 5,400 & Alexander (1989) \\
\hline & & 4,510 & Colbert (1962) \\
\hline & & 3,790 & Henderson (1999) \\
\hline Tenontosaurus & 243.0 & 600 & Spotila et al. (1991) \\
\hline Thescelosaurus & 7.9 & 310 & Anderson et al. (1985) \\
\hline \multicolumn{4}{|l|}{ Sauropoda } \\
\hline \multirow[t]{5}{*}{ Apatosaurus } & $22,407.2$ & 34,000 & Alexander (1989) \\
\hline & & 32,420 & Colbert (1962) \\
\hline & & 27,870 & Colbert (1962) \\
\hline & & 35,000 & Anderson et al. (1985) \\
\hline & & 19,500 & Christiansen (1997) \\
\hline \multirow[t]{6}{*}{ Brachiosaurus } & $28,264.6$ & 47,000 & Alexander (1989) \\
\hline & & 30,000 & Reid (1997) \\
\hline & & 32,000 & Paul (1988) \\
\hline & & 29,000 & Anderson et al. (1985) \\
\hline & & 78,260 & Colbert (1962) \\
\hline & & 37,400 & Christiansen (1997) \\
\hline Camarasaurus & $11,652.2$ & 8,800 & Christiansen (1997) \\
\hline Dicraeosaurus & $4,421.5$ & 5,400 & Christiansen (1997) \\
\hline \multirow{5}{*}{ Diplodocus } & $19,654.6$ & 13,421 & Henderson (1999) \\
\hline & & 10,560 & Colbert (1962) \\
\hline & & 18,500 & Alexander (1989) \\
\hline & & 5,000 & Anderson et al. (1985) \\
\hline & & 15,200 & Christiansen (1997) \\
\hline Mamenchisaurus & $18,169.7$ & 14,300 & Christiansen (1997) \\
\hline Omeisaurus & $11,796.0$ & 9,800 & Christiansen (1997) \\
\hline Opisthocoelicaudia & $10,522.2$ & 22,000 & Anderson et al. (1985) \\
\hline Shunosaurus & $4,793.5$ & 3,400 & Christiansen (1997) \\
\hline \multicolumn{4}{|l|}{ Stegosauria } \\
\hline \multirow{3}{*}{ Stegosaurus } & $2,610.6$ & 1,780 & Colbert (1962) \\
\hline & & 3,100 & Alexander (1989) \\
\hline & & 2,530 & Henderson (1999) \\
\hline \multicolumn{4}{|l|}{ Theropoda } \\
\hline Albertosaurus & $2,465.0$ & 2,500 & Paul (1988) \\
\hline \multirow{3}{*}{ Allosaurus } & 952.0 & 1,400 & Alexander (1989) \\
\hline & & 2,090 & Colbert (1962) \\
\hline & & 1,010 & Paul (1988) \\
\hline Archaeopteryx & 0.25 & 0.26 & Paul (1988) \\
\hline Avimimus & 22.2 & 14 & Paul (1988) \\
\hline \multirow[t]{2}{*}{ Ceratosaurus } & 472.6 & 670 & Anderson (1985) \\
\hline & & 524 & Paul (1988) \\
\hline Coelophysis & 16.0 & 15.3 & Paul (1988) \\
\hline Compsognathus & 3.5 & 2.5 & Paul (1988) \\
\hline Deinonychus & 104.7 & 75 & Spotila et al. (1991) \\
\hline Giganotosaurus & $6,594.9$ & $6,000+$ & Coria and Salgado (1995) \\
\hline Ornitholestes & 13.5 & 12.6 & Paul (1988) \\
\hline Ornithomimus & 585.7 & 440 & Paul (1988) \\
\hline Sinornithoides & 1.9 & 2.5 & Russell and Dong (1993) \\
\hline \multirow{6}{*}{ Tyrannosaurus } & $6,650.9$ & 7,400 & Alexander (1989) \\
\hline & & 5,700 & Paul (1988) \\
\hline & & 6,890 & Colbert (1962) \\
\hline & & 4,500 & Anderson (1985) \\
\hline & & 7,224 & Henderson (1999) \\
\hline & & 5,700 & Farlow (1990) \\
\hline Velociraptor & 44.3 & 45 & Paul (1988) \\
\hline
\end{tabular}

estimate and those of other authors (Fig. 4). There are, however, considerable differences in mass estimates reported in the literature for some species. For example, Colbert's (1962) mass estimate of $78,260 \mathrm{~kg}$ for Brachiosaurus is $30,000 \mathrm{~kg}$ heavier than the next closest estimate of Alexander (1989), and even Alexander's (1989) estimate exceeds my own and other esti- mates by nearly 20,000 kg (Fig. 4). Anderson et al.'s (1985) estimate of Opisthocoelicaudia is double that of my own estimate as well as more than double that of mass estimates for sauropods of similar length given in Christiansen (1997). On the other hand, Anderson et al.'s (1985) mass estimate of 5,000 $\mathrm{kg}$ for Diplodocus is only about one half to one quarter that of 


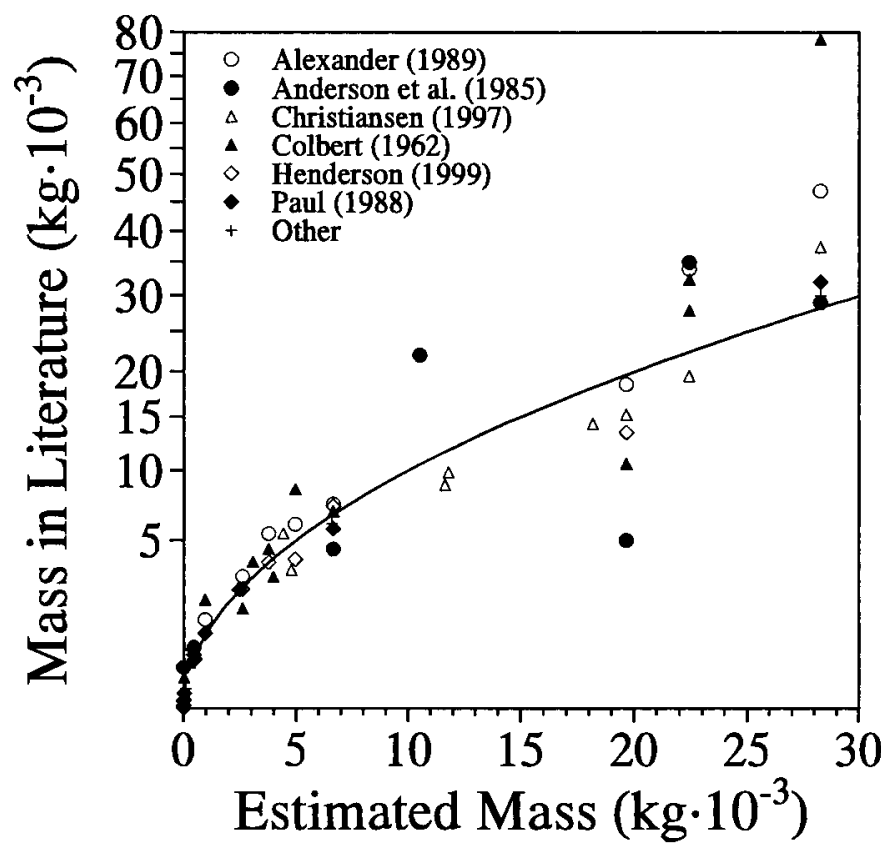

FIGURE 4. Mass estimates reported in the literature (y-axis) plotted against mass calculated by the polynomial method in this study (x-axis). Mass estimates by different authors are plotted separately (see legend), and there were no systematic differences between literature and polynomial mass estimates, although there are some outliers in the literature data (see text for discussion). Note that the $y$-axis is on a square root scale in order to improve the resolution at lower body mass. The line of equality $(y=x)$ is shown (solid line).

other authors', and their mass for Diplodocus is less than a quarter of their estimate of Opisthocoelicaudia which, however, is less than half the length of Diplodocus (Fig. 4). It seems unlikely that the huge differences in the examples above reflect the real size range of the species, and the discrepancies are more likely owing to methodology.

It is inevitable that mass estimates of extinct animals vary, because the representation of a fossil as a living animal, although based on skeletal remains and on knowledge of living animals, is always subject to personal interpretation. Hence, methods of mass estimation which rely on three dimensional models or on graphical representations include the artists' 'error' of reproducing what he or she thinks the animals looked like when it was alive.

Mass estimates from bone measurements are not subject to this error, but Christiansen (1999a) has shown that there are systematic differences in allometric scaling of appendicular bones between groups of extant mammals. Hence, this approach too will have an error attached to it which is difficult to quantify for extinct animals. Given this level of uncertainty, it is encouraging that, except for some outliers, mass estimates by the polynomial method agree fairly well with literature values and that there are no systematic differences, which also supports the validity and utility of the allometric equations for estimating body mass of dinosaurs.

\section{ACKNOWLEDGMENTS}

I would like to thank J. O. Farlow and P. Christiansen for comments and suggestions which have greatly improved this manuscript. Many thanks also go to T. Pople for making some of his macropod field data available to me.

\section{LITERATURE CITED}

Alexander, R. McN. 1985. Mechanics of posture and gait of some large dinosaurs. Zoological Journal of the Linnaean Society 83:1-25. 1989. Dynamics of Dinosaurs and Other Extinct Giants. Columbia University Press, New York, pp. 16-26.

Anderson, J. F., A. Hall-Martin, and D. A. Russell. 1985. Long bone circumference and weight in mammals, birds and dinosaurs. Journal of Zoology, London 207:53-61.

Benton, M. J., L. Juul, G. W. Storrs, and P. M. Galton. 2000. Anatomy and systematics of the prosauropod dinosaur Thecodontosaurus antiquus from the Upper Triassic of Southwest England. Journal of Vertebrate Paleontology 20:77-108.

Borsuk-Bialynicka, M. 1977. A new camarasaurid sauropod Opisthocoelicaudia skarzynskii gen. n., sp. n. from the Upper Cretaceous of Mongolia. Palaeontologia Polonica 37:5-64.

Brett-Surman, M. K. 1997. Ornithopods; pp. 330-346 in J. O. Farlow and M. K. Brett-Surman (eds.), The Complete Dinosaur. Indiana University Press, Indianapolis.

Brown, B., and E. M. Schlaikjer. 1940. The structure and relationships of Protoceratops. Annals of the New York Academy of Sciences 40:133-266.

Carpenter, K. 1981. Skeletal and dermal armour reconstruction of Euoplocephalus tutus (Ornithischia: Ankylosauridae) from the Late Cretaceous Oldman Formation of Alberta. Canadian Journal of Earth Science 19:689-697.

1984. Skeletal reconstruction and life restoration of Sauropelta (Ankylosauria: Nodosauridae) from the Cretaceous of North America. Canadian Journal of Earth Science 21:1491-1498.

1990. Pinacosaurus; pp. 208 in P. Dodson (ed.), Encyclopedia of Dinosaurs. Beekman House, New York.

1997. Ankylosaurs; pp. 307-316 in J. O. Farlow and M. K. Brett-Surman (eds.), The Complete Dinosaur. Indiana University Press, Indianapolis.

Christiansen, P. 1997. Locomotion in sauropod dinosaurs. Gaia 14:4575.

1999a. Scaling of mammalian long bones: small and large mammals compared. Journal of Zoology, London 247:333-348.

1999b. What size were Arctodus simus and Ursus spelaeus (Carnivora: Ursidae)? Annales Zoologici Fennici 36:93-102.

Colbert, E. H. 1962. The weights of dinosaurs. American Museum Novitates 2076:1-16.

Coria, R. A., and L. Salgado. 1995. A new giant carnivorous dinosaur from the Cretaceous of Patagonia. Nature 377:224-226. , and 1996. A basal iguanodontian (Ornithischia: Ornithopoda) from the Late Cretaceous of south America. Journal of Vertebrate Paleontology 16:445-457.

Coulson, R. A., and T. Hernandez. 1983. Alligator metabolism: studies on chemical reactions in vivo. Comparative Biochemistry and Physiology $74: 1-182$.

Currie, P. J. 1990. Elmisauridae; pp. 245-248 in D. B. Weishampel, P. Dodson, and H. Osmolska (eds.), The Dinosauria. University of California Press, Berkeley.

1996. Out of Africa: meat-eating dinosaurs that challenge Tyrannosaurus rex. Science 272:971-972.

1997. Theropods; pp. 216-233 in J. O. Farlow and M. K. BrettSurman (eds.), The Complete Dinosaur. Indiana University Press, Indianapolis.

, and X. Zhao. 1993. A new carnosaur (Dinosauria, Theropoda) from the Jurassic of Xinjiang, People's Republic of China. Canadian Journal of Earth Science 30:2037-2081.

, S. J. Godfrey, and Nessov, L. 1993. New caenagnathid (Dinosauria: Theropoda) specimens from the Upper Cretaceous of North America and Asia. Canadian Journal of Earth Science 30: 2255-2272.

Dal Sasso, C., and M. Signore. 1998. Exceptional soft-tissue preservation in a theropod dinosaur from Italy. Nature 392:383-387.

del Hoyo, J., A. Elliott, and J. Sargatal. 1992. Handbook of the Birds of the World, Vol. 1. Lynx Edicions, Barcelona, pp. 98-103.

Dong, Z., and Z. Tang. 1984. Note on a new Mid-Jurassic sauropod (Datousaurus bashanensis gen. et sp. nov.) from Sichuan Basin, China. Vertebrata Palasiatica 22:69-75.

Dong, Z. 1990. Stegosaurs of Asia; pp. 255-268 in K. Carpenter and P. J. Currie (eds.), Dinosaur Systematics. Approaches and Perspectives. Cambridge University Press, Cambridge. 

84

Dunham, A. E., K. L. Overall, W. P. Porter, and C. A. Forster. 1989. Implications of ecological energetics and biophysical and developmental constraints for life-history variation in dinosaurs; pp. 119 in J. O. Farlow (ed.), Paleobiology of the Dinosaurs. Geological Society of America Special Paper 238.

Farlow, J. O. 1990. Dynamic dinosaurs. Paleobiology 16:234-241.

1993. On the rareness of big, fierce animals: speculations about the body sizes, population densities, and geographic ranges of predatory mammals and large carnivorous dinosaurs. American Journal of Science 293A:167-199.

-, M. B. Smith, and J. M. Robinson. 1995. Body mass, bone "strength indicator," and cursorial potential of Tyrannosaurus rex. Journal of Vertebrate Paleontology 15:713-725.

Feduccia, A. 1999. The Origin and Evolution of Birds. Yale University Press, New Haven, pp. 93.

Forster, C. A., and P. C. Sereno. 1997. Marginocephalians; pp. 317-329 in J. O. Farlow and M. K. Brett-Surman (eds.), The Complete Dinosaur. Indiana University Press, Indianapolis.

Galton, P. M. 1970. The posture of hadrosaurian dinosaurs. Journal of Paleontology 44:464-473.

1974. The ornithischian dinosaur Hypsilophodon from the Wealden of the Isle of Wight. Bulletin of the British Museum of Natural History, Geology 25:1-152.

— 1977. The ornithopod dinosaur Dryosaurus and a LaurasiaGondwanaland connection in the Upper Jurassic. Nature 268:230232.

- 1986. Prosauropod dinosaur Plateosaurus (=Gresslyosaurus) (Saurischia: Sauropodomorpha) from the Upper Triassic of Switzerland. Geologica et Palaeontologica 20:167-183.

1997. Stegosaurs; pp. 291-306 in J. O. Farlow and M. K. BrettSurman (eds.), The Complete Dinosaur. Indiana University Press, Indianapolis.

- , and H. P. Powell. 1980. The ornithischian dinosaur Camptosaurus prestwichii from the Upper Jurassic of England. Palaeontology 23:441-443.

Gillette, D. D. 1991. Seismosaurus halli (n. gen., n. sp.) a new sauropod dinosaur from the Morrison Formation (Upper Jurassic-Lower Cretaceous) of New Mexico, U.S.A. Journal of Vertebrate Paleontology 11:417-433.

Godefroit, P., Z. Dong, P. Bultynck, H. Li, and L. Feng. 1998. SinoBelgian Cooperation Program "Cretaceous dinosaurs and mammals from Inner Mongolia” 1. New Bactrosaurus (Dinosauria: Hadrosauridae) material from Iren Dabasu (Inner Mongolia, P. R. China). Bulletin de L'Institut Royal des Sciences Naturelles de Belgique Sciences de la Terre 68-Supp:3-70.

He, X., K. Li, and K. Cai. 1988. Sauropod Dinosaurs 2 Omeisaurus tianfuensis. The middle Jurassic Dinosaur Fauna from Dashanpu, Zigong, Sichuan, Vol. IV. Sichuan Publishing House of Science and Technology, Chengdu, China, pp. 80-143.

Heinrich, R. E., C. B. Ruff, and D. B. Weishampel. 1993. Femoral ontogeny and locomotor biomechanics of Dryosaurus lettowvorbecki (Dinosauria: Iguanodontia). Zoological Journal of the Linnaean Society 108:179-196.

Henderson, D. M. 1999. Estimating the masses and centers of mass of extinct animals by 3-D mathematical slicing. Paleobiology 25:88106.

Holland, W. J. 1910. A review of some recent criticism of the restorations of sauropod dinosaurs existing in the museums of the United States, with special reference to that of Diplodocus carnegiei in the Carnegie Museum. American Naturalist 44:259-283.

Holtz, T. R. jr. 1994. The phylogenetic position of the Tyrannosauridae: implications for theropod systematics. Journal of Paleontology 68: $1100-1117$.

Hurlburt, G. 1999. Comparison of body mass extinction techniques, using recent reptiles and the pelycosaur Edaphosaurus boanerges. Journal of Vertebrate Paleontology 19:338-350.

Lucas, S. G. 1994. Dinosaurs: the Textbook. C. Brown Publishers, Dubuque, Iowa, pp. 139.

Martill, D.M., E. Frey, H.-D. Sues, and A. R. I. Cruickshank. 2000. Skeletal remains of a small theropod dinosaur with associated soft structures from the Lower Cretaceous Santana Formation of northeastern Brazil. Canadian Journal of Earth Sciences 37:1-10.

McIntosh, J. S., W. E. Miller, K. L. Stadtman, and D. D. Gillette. 1996.
The osteology of Camarasaurus lewisi (Jensen, 1988). Brigham Young University Geology Studies 41:73-116.

, M. K. Brett-Surman, and J. O. Farlow. 1997. Sauropods; pp. 264-290 in J. O. Farlow and M. K. Brett-Surman (eds.), The Complete Dinosaur. Indiana University Press, Indianapolis.

Norman, D. B. 1980. On the ornithischian dinosaur Iguanodon bernissartensis from the Lower Cretaceous of Bernissart (Belgium). Institut Royal des Sciences Naturelles de Belgique Memoire 178:1103.

, and D. B. Weishampel. 1990. Iguanodontidae and related ornithopods; pp. 510-533 in D. B. Weishampel, P. Dodson and $\mathrm{H}$. Osmólska (eds.), The Dinosauria. University of California Press, Berkeley.

Ostrom, J. H. 1969. Osteology of Deinonychus antirrhopus, an unusual theropod from the Lower Cretaceous of Montana. Peabody Museum of Natural History Bulletin 30:1-165.

1978. The osteology of Compsognathus longipes Wagner. Zitteliana 4:73-118.

, and P. Wellnhofer. 1985. The Munich specimen of Triceratops with a revision of the genus. Zitteliana 14:111-158.

Padian, K., J. R. Hutchinson, and T. R. Holtz, Jr. 1999. Phylogenetic definitions and nomenclature of the major taxonomic categories of the carnivorous Dinosauria (Theropoda). Journal of Vertebrate Paleontology 19:69-80.

Paul, G. S. 1988. Predatory Dinosaurs of the World. Simon and Schuster, New York, pp. 226-264.

1990. Chasmosaurus, Homocephale, Monoclonius, Pentaceratops, Bactrosaurus, Massospondylus, Omeisaurus, Stegosaurus, pp. 58-215 in P. Dodson (ed.), Encyclopedia of Dinosaurs. Beekman House, New York.

Reid, R. E. H. 1997. Dinosaur Physiology: The case for "intermediate" dinosaurs; pp. 449-473 in J. O. Farlow and M. K. Brett-Surman (eds.), The Complete Dinosaur. Indiana University Press, Indianapolis.

Riggs, E. S. 1903. Brachiosaurus altithorax, the largest known dinosaur. American Journal of Science 15:299-306.

Rozhdestvensky, A. K. 1966. [New iguanodonts from Central Asia. Phylogenetic and taxonomic relationships between late Iguanodontidae and early Hadrosauridae]. Paleontologicheskii Zhurnal 1966: 103-116 [Russian].

Ruben, J. A., T. D. Jones, N. R. Geist, and W. J. Hillenius. 1997. Lung structure and ventilation in theropod dinosaurs and early birds. Science 278:1267-1270.

Russell, D. A., and Z. Dong. 1993a. The affinities of a new theropod from the Alxa Desert, Inner Mongolia, People's Republic of China. Canadian Journal of Earth Sciences 30:2107-2127.

— dinosaur from the Early Cretaceous of the Ordos Basin, Inner Mongolia, People's Republic of China. Canadian Journal of Earth Sciences 30:2163-2173.

Salgado, L., and J. F. Bonaparte. 1991. Un nuevo sauropodo Dicraeosauridae, Amargasaurus cazaui gen. et sp. nov., de la formacion La Amarga, Neocomiano de la provincia del Neuquen, Argentina. Ameghiniana 28:333-346.

Schmidt-Nielsen, K. 1984. Scaling: Why is Animal Size so Important? Cambridge University Press, Cambridge, 33 pp.

Seebacher, F., G. C. Grigg, and L. A. Beard. 1999. Crocodiles as Dinosaurs: behavioural thermoregulation in very large ectotherms leads to high and stable body temperatures. Journal of Experimental Biology 202:77-86.

Sereno, P. C. 1990. New data on parrot-beaked dinosaurs (Psittacosaurus); pp. 203-210 in K. Carpenter and P. J. Currie (eds.), Dinosaur Systematics: Perspectives and Approaches. Cambridge University Press, Cambridge.

1999. The evolution of dinosaurs. Science 284:2137-2147.

, and F. E. Novas. 1992. The complete skeleton of an early dinosaur. Science 258:1137-1140.

, C. A. Forster, R. R. Rogers, and A. M. Monetta. 1993. Primitive dinosaur skeleton from Argentina and the early evolution of Dinosauria. Nature 361:64-66.

, J. A. Wilson, H. C. E. Larsson, D. B. Dutheil, and H. Sues 1994. Early Cretaceous dinosaurs from the Sahara. Science 266 : 267-271.

, D. B. Dutheil, M. Iarochene, H. C. E. Larsson, G. H. Lyon, P. M. Magwene, C. A. Sidor, D. J. Varricchio, and J. A. Wilson. 1996 
Predatory dinosaurs from the Sahara and Late Cretaceous faunal differentiation. Science 272:986-991.

, A. L. Beck, D. B. Dutheil, B. Gado, H. C. E. Larsson, G. H. Lyon, J. D. Marcot, O. W. M. Rauhut, R. W. Sadleir, C. A. Sidor, D. D. Varricchio, G. P. Wilson, and J. A. Wilson. 1998. A long snouted predatory dinosaur from Africa and the evolution of spinosaurids. Science 282:1298-1302.

Sokal, R. P., and F. J. Rohlf. 1980. Biometry. W. H. Freeman and Company, pp. 458-571.

Spotila, J. R., M. P. O'Connor, P. Dodson, and F. V. Paladino. 1991. Hot and cold running dinosaurs: body size, metabolism and migration. Modern Geology 16:203-227.

Stewart, J. 1991. Calculus. Brooks/Cole Publishing Company, Pacific Grove, California, pp. 309-317.

Sues, H.-D., and D. B. Norman. 1990. Hypsilophodontidae, Tenontosaurus, Dryosauridae; pp. 498-509 in D. B. Weishampel, P. Dodson and H. Osmólska (eds.), The Dinosauria. University of California Press, Berkeley.
Van Heerden, J. 1997. Prosauropods; pp. 330-346 in J. O. Farlow and M. K. Brett-Surman (eds.), The Complete Dinosaur. Indiana University Press, Indianapolis.

Walker, E. P., F. Warnick, K. I. Lange, H. E. Uible, S. E. Hamlet, M. A. Davis, and P. F. Wright. 1964. Mammals of the World, Vol. II. Johns Hopkins Press, Baltimore, pp. 1321-1408.

Weishampel, D. B., and J. H. Horner. 1990. Hadrosauridae; pp. 534 561 in D. B. Weishampel, P. Dodson and H. Osmólska (eds.), The Dinosauria. University of California Press, Berkeley.

West, G. B., J. H. Brown, and B. J. Enquist. 1997. A general model for the origin of allometric scaling laws in biology. Science 276:122126.

Zhang, Y. 1988. Sauropod Dinosaurs (I) Shunosaurus. The Middle Jurassic Dinosaur Fauna from Dashanpu, Zigong, Sichuan, Vol. I. Sichuan Scientific and Technological Publishing House, Chengdu, China, pp. 42-67.

Zhou, S. 1984. Stegosaurs. The Middle Jurassic Dinosaurian Fauna from Dashanpu, Zidong, Sichuan, Vol. II. Sichuan Scientific and Technological Publishing House, Chengdu, China, pp. 32-40. 